\title{
Relationship between fibropapillomatosis and environmental quality: a case study with Chelonia mydas off Brazil
}

\author{
Robson Guimarães dos Santos ${ }^{1, *}$, Agnaldo Silva Martins ${ }^{1}$, Evelise Torezani ${ }^{2}$, \\ Cecília Baptistotte ${ }^{2}$, Julyana da Nóbrega Farias ${ }^{3}$, Paulo Antunes Horta ${ }^{3}$, \\ Thierry M. Work ${ }^{4}$, George H. Balazs ${ }^{5}$ \\ ${ }^{1}$ Departamento de Oceanografia e Ecologia, CCHN, Universidade Federal do Espírito Santo, 29075-910, Vitória, \\ ES, Brasil \\ ${ }^{2}$ Projeto TAMAR-ICMBio, Escritório Regional de Vitória, 29040-715, Vitória, ES, Brasil \\ ${ }^{3}$ Departamento de Botânica, CCB, Universidade Federal de Santa Catarina, 88010-970, Florianópolis, SC, Brasil \\ ${ }^{4}$ US Geological Survey, National Wildlife Health Center, Honolulu Field Station, PO Box 50167, Honolulu, \\ Hawaii 96850, USA \\ ${ }^{5}$ NOAA-National Marine Fisheries Service, Pacific Islands Fisheries Science Center, 2570 Dole St., Honolulu, \\ Hawaii 96822, USA
}

\begin{abstract}
We documented the presence of fibropapillomatosis (FP), a debilitating tumor-forming disease, in marine turtles in Espírito Santo Bay (Brazil) from March 2007 to April 2008, and assessed the value of a specific environmental index for predicting the prevalence of FP. Turtles were captured monthly with entanglement nets and scored for presence and severity of FP. For the assessment of habitat quality, we used the ecological evaluation index (EEI) based on benthic macrophytes. The FPfree control area was classified as good quality $(\mathrm{EEI}=8)$ and the study area, with high FP prevalence, was classified as bad quality $(E E I=2)$. Prevalence of FP in the study area was $58.3 \%$ with an average of 40 tumors per individual, and prevalence varied positively with curved carapace length (CCL). No FP was seen in the control area. The number of turtles heavily afflicted (tumor score category 3 ) was 10 times larger than those lightly affected (tumor score category 1). Most tumors were found on or near the front and rear flippers; no oral tumors or internal tumors were found. At recapture, $41 \%$ of formerly tumor-free turtles revealed FP, often increasing in severity with time, and very few turtles showed signs of disease regression. From the results of this study we concluded that FP is particularly severe in Espírito Santo Bay. Future studies should focus on evaluating how widespread FP is in Brazil, whether prevalence is increasing or decreasing, and elucidating the pathology and pathogenesis of FP in sea turtles in Brazil.
\end{abstract}

KEY WORDS: Fibropapillomatosis · Environmental quality · Chelonia mydas · Green turtle · Ecological index $\cdot$ Brazil

\section{INTRODUCTION}

The knowledge of the health status of populations is considered an imperative to the development of conservation programs (Deem et al. 2001). The development of coastal regions is exerting increasing adverse impact on coastal ecosystems, sometimes leading to the exclusion or extinction of species (Daszak et al. 2000, Worm et al. 2006). Among the marine animals that make use of coastal areas are herbivorous green turtles Chelonia mydas, which are considered an endangered species by the International Union for 
Conservation of Nature and Natural Resources (IUCN) (Seminoff 2004). In addition to anthropogenic threats, diseases such as fibropapillomatosis (FP) may pose additional threats to Chelonia mydas (Herbst 1994, Aguirre et al. 1998).

FP is a debilitating disease affecting marine turtles that can impair foraging and internal organ function; it is characterized by the development of tumors on the eyes, oral cavity, skin, carapace, plastron or internal organs (Balazs 1991, Jacobson et al. 1991, Herbst 1994, Aguirre et al. 2002, Work et al. 2004, Foley et al. 2005). The disease mainly affects green turtles (Herbst 1994, Aguirre et al. 1998, 2002), but it has also been documented in other species (George 1997). FP is associated with a herpesvirus (Herbst 1994, Quackenbush et al. 1998), but the role of this agent in causing disease has not been clarified, and it appears other, as yet unidentified, factors probably play a role. It is known that turtles afflicted with FP have higher parasite loads (Work et al. 2005), are immunosuppressed (Work et al. 2001) and bacteraemic (Work et al. 2003).

Considerable geographical variation in the prevalence of FP exists (0 to $92 \%$ ), and substantial differences may be found even between relatively close areas (Ehrhart 1991, Herbst 1994, Hirama \& Ehrhart 2007). In addition to geographic variation, there is also variation in severity and nature of the disease as determined by size, location, and quantity of tumors (Adnyana et al. 1997, Work \& Balazs 1999, Hirama \& Ehrhart 2007). For example, tumors are present in the oral cavity of Hawaiian green turtles but are rare in the oral cavity of Florida green turtles (Aguirre et al. 2002). Despite the suspicion that geographic area and habitat quality may play a role in the presence of FP (Herbst 1994, Herbst \& Klein 1995) and explain the association of the disease with inshore areas and pollution (Foley et al. 2005, Hirama \& Ehrhart 2007), there are to date no studies to objectively quantify this association. However, various indices for quantifying environmental quality exist for marine ecosystems (Orfanidis et al. 2001, 2003), and applying these in relation to the prevalence of FP may shed light on the relationship between environmental parameters and FP disease in marine turtles.

This work was conducted in a degraded feeding area of Chelonia mydas in Espírito Santo, Brazil: the state where FP was first documented in the country in 1986, and where it has been endemic since (Baptistotte et al. 2001). The objectives of this study were to: (1) assess the prevalence and severity of FP in benthic green turtles in Espírito Santo Bay, Brazil and (2) evaluate the association of a specific environmental index using presence/absence of macroalgae (Orfanidis et al. 2001, 2003) with the prevalence of FP.

\section{MATERIALS AND METHODS}

Study site. Our FP-endemic area in the bay of Espírito Santo is an area of dense urbanization, traffic with a major port producing significant commercial activity along the southeastern coast of Brazil. The bay receives runoff from domestic residences as well as light and heavy industry. The study site was a green turtle feeding area located between Frade Island and the mainland (Fig. 1), having a depth of 1 to $3 \mathrm{~m}$ and a temperature of 22 to $26^{\circ} \mathrm{C}$.

We chose Fernando de Noronha archipelago for our control area, a pristine feeding area for Chelonia mydas (Bellini 1996) that presents a seaweed community composition potentially similar to that in Espírito Santo Bay (Horta et al. 2001). The archipelago is located $344 \mathrm{~km}$ from the northeast Brazilian coastline, and turtles there have been monitored by the TAMAR/ICMBio project since 1987 through a program of capture-mark-recapture (Bellini 1996). The control area is located more than $2000 \mathrm{~km}$ from the FPendemic area; no movement of green turtles between these 2 areas has been recorded.

Environmental quality evaluation. For assessment of environmental quality, we used the ecological evaluation index (EEI: Orfanidis et al. 2001, 2003). The EEI uses abundance of marine benthic macrophyte (seagrass and seaweed) species to estimate the ecological status of an area by placing them into 2 ecological state groups (ESG): ESG I includes algae with a thick or calcareous thallus, low growth rates and long life cycles (late successionals); ESG II includes algae with sheetlike and filamentous morphology, with high growth rates and short life cycles (opportunistic). Using the abundance $(\%)$ of species in each ESG, an ecological status class (ESC) is generated (Table 1) representing the environmental quality, ranging from 'bad' $(\mathrm{EEI}=2)$ to 'high' (EEI = 10) (Orfanidis et al. 2001, 2003).

Table 1. Estimation of ecological evaluation index (EEI) and the equivalent ecological status class (ESC) from the abundance of ecological state groups (ESGs). Modified from Orfanidis et al. (2003)

\begin{tabular}{|lccr|}
\hline $\begin{array}{l}\text { Mean coverage } \\
\text { of ESG I (\%) }\end{array}$ & $\begin{array}{c}\text { Mean coverage of } \\
\text { ESG II }(\%)\end{array}$ & ESC & EEI \\
\hline $0-30$ & $0-30$ & Moderate & 6 \\
& $>30-60$ & Low & 4 \\
& $>60$ & Bad & 2 \\
$>30-60$ & $0-30$ & Good & 8 \\
& $>30-60$ & Moderate & 6 \\
& $>60$ & Low & 4 \\
& $0-30$ & High & 10 \\
& $>30-60$ & Good & 8 \\
& $>60$ & Moderate & 6 \\
\hline
\end{tabular}


The EEI for both FP-endemic and control areas was calculated by estimating the abundance (\%) of ESG I and ESG II groups of algae in 2007-2008. Algae were quantified by counting species in 20 and 40 haphazardly placed quadrats in the control and FP-endemic areas, respectively. The number of quadrats was based on preliminary sampling analyses and community heterogeneity estimates as per Murray et al. (2002). A Shannon-Wiener diversity index was calculated according to Magurran (1991).

Turtle capture and measurements. Two entanglement nets $(450 \mathrm{~m} \times 10 \mathrm{~m}$; mesh size $=10 \mathrm{~cm})$ were placed together end to end, forming a barrier. The

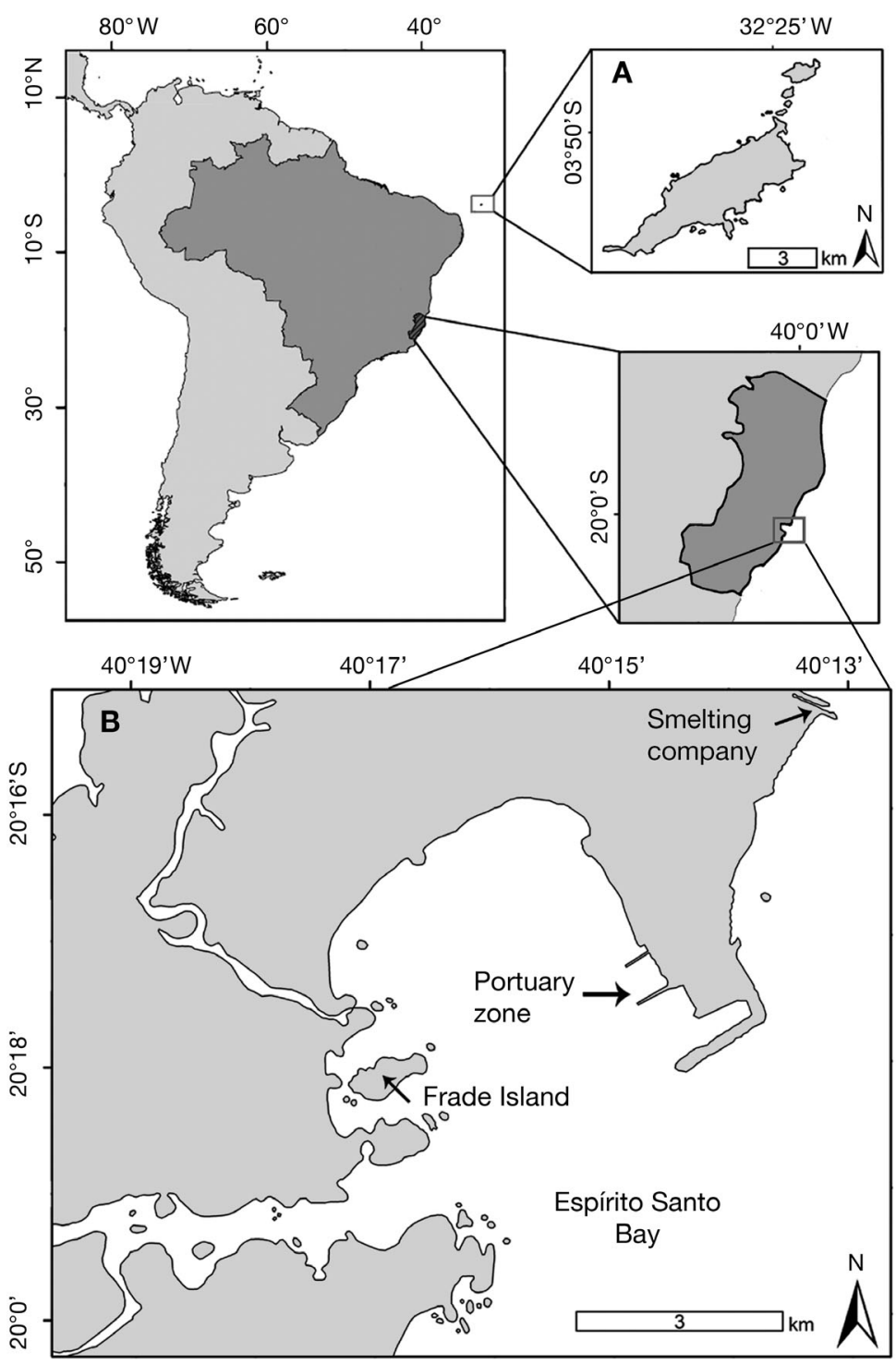

Fig. 1. (A) Control area, Fernando de Noronha Archipelago. (B) Fibropapillomatosis-endemic study area, between Frade Island and the mainland, located in Espírito Santo Bay, east coast of Brazil, southwestern Atlantic nets were deployed once a month for $4 \mathrm{~h}$ from March 2007 to April 2008 (except in January and February 2008, when capture was not possible due to logistical problems). The nets were constantly monitored; all of the captured turtles were removed and taken to the beach for processing. The curved carapace length $(\mathrm{CCL} ; \pm 0.1 \mathrm{~cm})$ was measured with flexible plastic metric tape, and individuals were marked on their 2 anterior flippers with Inconel alloy tags (Style 681C, National Band and Tag Co.), following standard methodology adopted by Project TAMAR/ICMBio. Care was taken in the handling of turtles so that neither FP-affected individuals, nor the material used on these animals, came into contact with nonaffected individuals. Before being released, all animals were weighed $( \pm 0.1 \mathrm{~kg})$. Individuals with CCL >101 cm were considered sexually mature based on the smallest registered size for nesting females in the largest, and closest, nesting area for this species in Brazil (Moreira et al. 1995). The CCL was converted to straight carapace length (SCL) using the equation described in Bjorndal \& Bolten (1989); body condition index $\left(\mathrm{BCI}=\right.$ body mass $/ \mathrm{SCL}^{3}$ ) was calculated as described by Bjorndal et al. (2000).

Evaluation of fibropapillomatosis manifestation. All captured turtles were examined for presence of external or oral cavity tumors, and we recorded the number, location and size of tumors for each turtle. The tumors were classified into 4 size categories according to largest diameter: $(\mathrm{A})<1 \mathrm{~cm}$, (B) 1-4 cm, (C) $>4-10 \mathrm{~cm}$ and (D) $>10 \mathrm{~cm}$ (Work \& Balazs 1999). Using the number of tumors and tumor size category, turtles were assigned a subjective index of FP severity (FP score or FPS); this ranged from FPS-0 (tumor-free) to FPS-3 (heavily tumored: Balazs 1991, Work \& Balazs 1999). Though the FPS is subjective, it is considered a reliable index of physiological effects of FP (Work \& Balazs 1999, Aguirre \& Balazs 2000, Work et al. 2001, 2003, 2004) and may be linked with adverse effects on turtle growth (Chaloupka \& Balazs 2005). To evaluate the tumor distribution throughout the body, each turtle was divided in 5 regions see (see Fig. 5). Dead turtles found stranded in the FP-endemic area were necropsied in the laboratory to document the presence of internal tumors.

Statistical analysis. The average difference between CCL and BCI in turtles with and without FP, and the BCI of individuals 
with and without eye tumors, was evaluated with the Mann Whitney- $U$ test. The average difference between CCL and BCI among FP severity scores (FPS) was evaluated with the Kruskal-Wallis test, followed by a Dunn post-hoc test for multiple comparisons. All data were analyzed using Statistic 6.0 (JMP).

Multi-dimensional scaling (MDS) analyses (Kruskal $\&$ Wish 1978) were employed to illustrate the pattern of FP severity score (FPS) distribution in captured individuals. The Bray-Curtis similarity matrix was generated from the number of tumors in each tumor size class (A to D), for each individual; verification of the differences between FPS was conducted through analysis of similarity (ANOSIM: Clarke 1993). These non-parametric analyses were calculated using the software Primer 5.0 (Primer E).

\section{RESULTS}

\section{Environmental quality evaluation}

Within the control area, the abundance (\%) of ESG I species was $67.4 \%$ and the abundance of ESG II species was $32.6 \%$, generating an EEI $=8$ and thereby classifying this area as of good quality. In contrast, within the area endemic for FP, all seaweed species found in the impacted site belonged to ESG II: opportunistic algae with fast growth and short life cycles (Orfanidis et al. 2003). Based on the $100 \%$ abundance of ESG II species, the FP site was of bad quality with an EEI of 2 (Table 2).

The Shannon-Wiener diversity index was calculated to be 0.04 in the FP-endemic area, and 0.99 in the control area.

Table 2. Abundance (\%) and ecological state group (ESG) of algae species from control area and fibropapillomatosisendemic (FP-endemic) area; ESG I = late successional species; ESG II = opportunistic species

\begin{tabular}{|lcc|}
\hline Algae species & Abundance (\%) & ESG \\
\hline Control area & & \\
Coralline algae & 34.0 & I \\
Halimeda discoidea & 0.4 & I \\
Padina gymnospora & 14.0 & I \\
Sargassum hystrix & 19.0 & I \\
Dictyota spp. & 32.6 & II \\
FP-endemic area & & \\
Acanthophora spicifera & 1.2 & II \\
Caulerpa mexicana & 89.8 & II \\
Ulva spp. & 4.2 & II \\
Dictyopteris delicatula & 4.8 & II \\
\hline
\end{tabular}

\section{Fibropapillomatosis prevalence and severity}

In the control area, 501 green turtles were captured and evaluated since 2000; the average CCL for these was $52.2 \mathrm{~cm}$ (range: 15.5 to $88.0 \mathrm{~cm}$ ) and no FP was documented (Baptistotte 2007).

We made 211 captures comprising 163 turtles (multiple recaptures account for the discrepancy) within the FP-endemic area; the average CCL was $42.1 \mathrm{~cm}$ (SD: $6.2 \mathrm{~cm}$; range: 29.2 to $71.2 \mathrm{~cm}$ ) and the average weight was $9.6 \mathrm{~kg}$ (SD: $4.9 \mathrm{~kg}$; range: 2.9 to $50 \mathrm{~kg}$ ). All of the turtles were considered immature. Prevalence of FP was $58.3 \%$ (95\% confidence interval: 50.3 to $65.9 \%$ ), with the average tumor number of 40 (SD: 20; range: 2 to 91 tumors). Prevalence of FP increased with CCL, peaking at $45-50 \mathrm{~cm}$ and decreasing thereafter (Fig. 2). The average CCL of the individuals with FPS-2 and FPS-3 was significantly higher than non-afflicted turtles ( $p=0.0001)$; however, we saw no significant difference in CCL between FPS-0 and FPS-1 turtles (Fig. 3 ). We saw no significant difference in body condition between the 4 tumor score categories.

Of the 87 turtles assigned a tumor score, 82 had tumor scores 2 or 3 (Table 3). With ANOSIM, a higher similarity between moderately (FPS-2) and heavily (FPS-3) afflicted individuals ( $\mathrm{R}=0.541 ; \mathrm{p}=0.1 \%$ ) was seen than between moderately and lightly afflicted (FPS-1) individuals ( $\mathrm{R}=0.692 ; \mathrm{p}=0.1 \%$ : Fig. 4).

\section{Distribution of tumors on turtles}

Body distribution of tumors was analyzed for 87 turtles. The most affected region was the anterior, followed by the posterior, eyes and carapace/plastron. Distribution analysis of tumors on the body within each

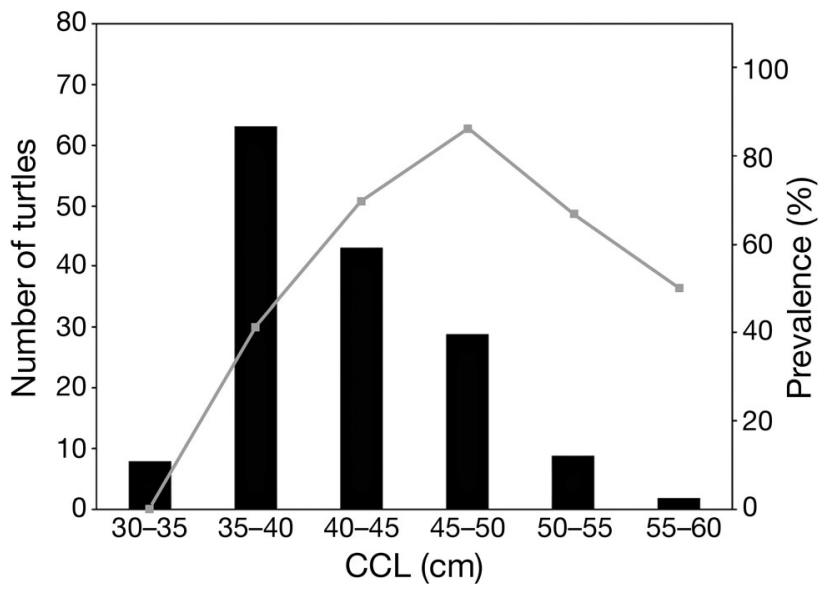

Fig. 2. Chelonia mydas. (Line) Prevalence variation of fibropapillomatosis in juveniles and (bars) number of turtles in each curved carapace length (CCL) size class (Espírito Santo Bay) 


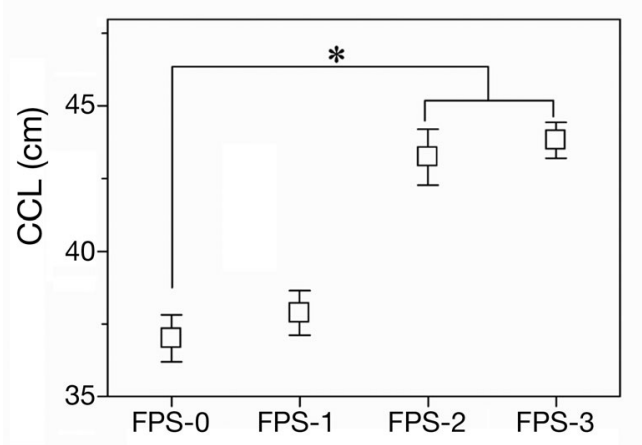

Fig. 3. Chelonia mydas. Relation between curved carapace length (CCL) and fibropapillomatosis severity scores (FPS) from individuals captured in Espírito Santo Bay. Data are expressed as mean \pm SE for each group. Lightly afflicted $=$ FPS-1 $(\mathrm{n}=5)$, moderately afflicted = FPS-2 $(\mathrm{n}=31)$, heavily afflicted $=$ FPS-3 $(\mathrm{n}=51)$. ${ }^{*}$ Significant difference between FPS-0 and FPS-2 ( $<<0.0001)$; FPS- 0 and FPS-3 ( $p<0.0001$ : KruskalWallis test, followed by a Dunn post-hoc test for multiple comparisons)

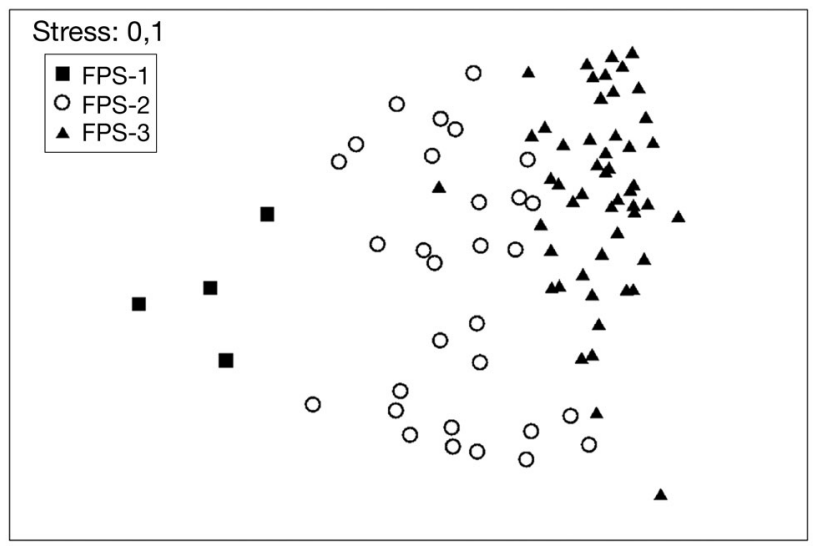

Fig. 4. Chelonia mydas. MDS graphical analysis of the relation between fibropapillomatosis severity scores (FPS) of 87 individuals captured in Espírito Santo Bay. Lightly afflicted = FPS-1, moderately afflicted = FPS-2, heavily afflicted $=$ FPS-3

Table 3. Chelonia mydas. Mean number of tumors per individual in each tumor size class (A to D) and fibropapillomatosis severity score (FPS) in juveniles captured in Espírito Santo Bay. FPS-1 = lightly afflicted $(\mathrm{n}=5), \mathrm{FPS}-2=$ moderately afflicted $(n=31)$, FPS-3 = heavily afflicted $(n=51)$

\begin{tabular}{|lcrr|}
\hline Tumor size class $(\mathrm{cm})$ & FPS-1 & FPS-2 & FPS-3 \\
\hline (A) $<1$ & 2.8 & 11.9 & 17.7 \\
(B) $1-4$ & 1.0 & 9.7 & 34.6 \\
(C) $>4-10$ & 0.0 & 0.3 & 2.0 \\
(D) $>10$ & 0.0 & 0.0 & 0.1 \\
Total & 3.8 & 21.9 & 54.2 \\
\hline
\end{tabular}

FPS shows a high predominance of tumors in the anterior and posterior regions for all FPS; there were relatively fewer tumors on the carapace/plastron region, with none found in this region for animals with FPS-1 (Fig. 5). Among 87 green turtles, 75.9\% showed eye tumors; however, only tumor size A and B were registered. The BCI for individuals with eye tumors showed no significant difference from the ones without eye tumors. Twenty dead turtles ( 9 without body tumors, 9 with FPS-2, and 2 with FPS-3) found stranded in the FP study area during the study period were necropsied, and no internal tumors were found.

\section{Analysis of fibropapillomatosis in recaptured individuals}

During the study period, 37 individuals were recaptured one or more times. In 12 turtles initially captured with no tumors, 7 (58.3\%) had no tumors on recapture and $5(41.7 \%)$ displayed tumors on recapture; of these 5 turtles, 1 increased from FPS-0 to FPS-1 (after $78 \mathrm{~d}$ ), 2 to FPS-2 (after 165 and 58 d, respectively), 1 to FPS-3 (after $75 \mathrm{~d}$ ) and tumors were not measured in the last turtle. In all cases, the disease initially manifested itself on the anterior $(n=1)$ or posterior regions $(n=1)$, or on both regions $(\mathrm{n}=2)$; no tumors were found on carapace and plastron.

Of recaptured individuals that already had FP on their initial capture, the average number of tumors increased from 34 to 39 tumors. Out of 25 individuals analyzed, 16 maintained the same FPS score, 6 changed to a higher FPS ( 2 from FPS- 1 to FPS- 2 and 4 from FPS-2 to FPS-3); 3 descended from FPS-3 to FPS-2. No turtle reverted from tumored to tumor-free.

\section{DISCUSSION}

\section{Environmental quality and fibropapillomatosis}

We used the EEI index (Orfanidis et al. 2001) for 3 reasons. Firstly, benthic algae are valuable indicators of water quality (e.g. Gorostiaga \& Díez 1996, Orfanidis et al. 2001, Ballesteros et al. 2007) because, as photosynthetic sessile organisms, their community structure responds directly to abiotic and biotic perturbations, thereby integrating the effects of long-term exposure to nutrients or pollutants (Murray \& Litter 1978). Secondly, macroalgae are abundant as food in developmental and feeding habitats of Chelonia mydas. Thirdly, the EEI has already been successfully applied to assess marine habitat quality (Orfanidis et al. 2001, Panayotidis et al. 2004).

The high prevalence of FP, the low quality of the habitat, and the low diversity of algae at the FP- 


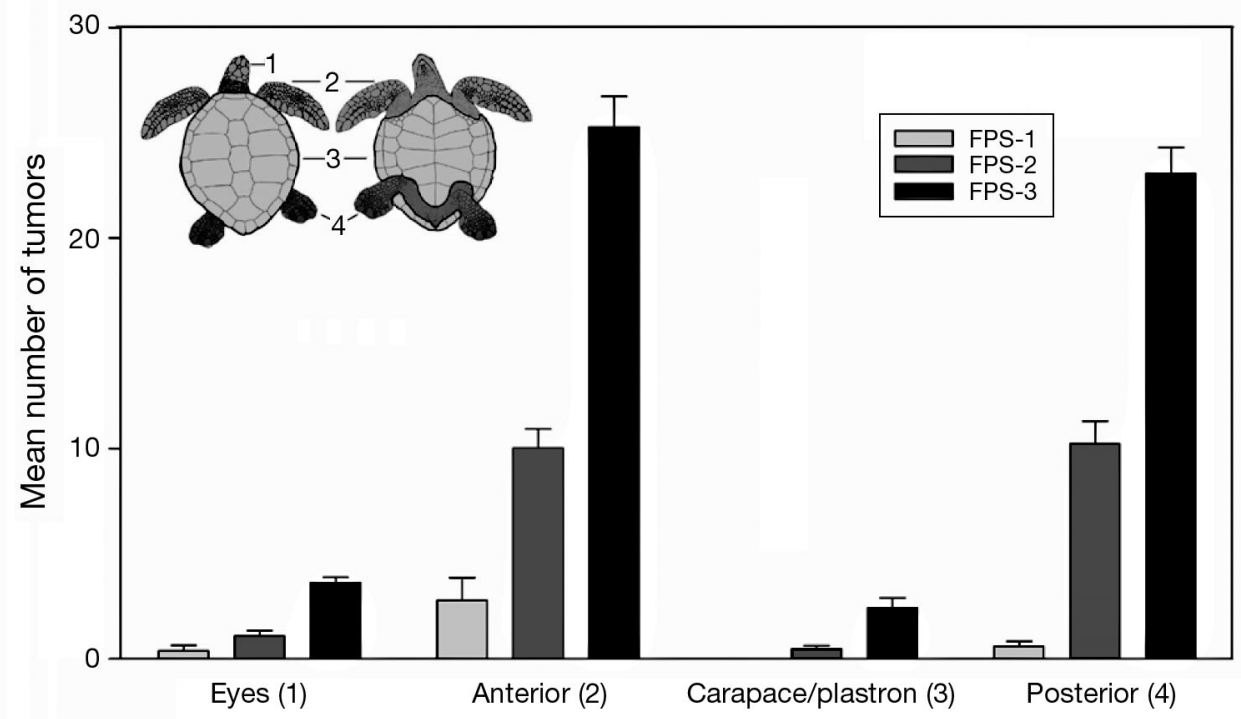

Fig. 5. Chelonia mydas. Tumor distribution per body region for different fibropapillomatosis severity scores (FPS: data from 87 individuals captured in Espírito Santo Bay). Data are expressed as mean + SD for each group. Lightly afflicted = FPS-1, moderately afflicted $=$ FPS-2, heavily afflicted $=$ FPS-3

endemic study area, contrasted with the absence of FP and good quality habitat found in the FP-free control area. These findings agree with the hypothesized relation between habitat degradation and presence of FP (Herbst 1994, Herbst \& Klein 1995). Our study is the first to quantify habitat quality relative to presence of FP. The utility of the ecological index in relation to FP could be applied to areas of intermediate FP prevalence such as the TAMAR/ICMBio capture site, located less than $10 \mathrm{~km}$ from our study area, where the prevalence of FP is 3 times smaller (18\%) than what we observed at our study site (TAMAR's database). The TAMAR/ICMBio site receives effluent from a smelting company, and is presumably degraded to some extent. Presumably, if the EEI were applied to this site, it should score intermediately between Espírito Santo Bay and Fernando de Noronha Archipelago. Future efforts should focus on confirming the utility of the EEI in relation to prevalence of FP in sea turtles in other regions of Brazil.

To date, our knowledge of the relationship between altered macroalgal community and prevalence of FP has not been quantified. While our findings are purely associative at this point, the predominance of opportunistic fast growing algae in the FP-endemic area could have a nutritional impact on benthic phase green turtles that exhibit strong fidelity to a specific foraging area (Godley et al. 2003), and which depend mainly on macroalgae and/or seagrass for sustenance (Bjorndal 1997). This could set the stage for chronic exposure to bioaccumulated contaminants in algae or the absence of essential nutrients that could exacerbate susceptibility to, or development of, FP. While other factors such as immunosuppression are strongly correlated with FP in wild green turtles (Work et al. 2001), the impact of altered dietary quality/diversity and nutrition as contributory factors have not been explored, and merit further investigation.

\section{Prevalence and severity}

The FP prevalence of $58.3 \%$ in our study site was high compared to other areas in Brazil where general prevalence is lower (15.4\%: Baptistotte 2007). Compared to other regions of the world (Herbst 1994), and in more recent publications (Adnyana et al. 1997, Hirama \& Ehrhart 2007), our study site had the 8th highest prevalence of FP among the 42 evaluated in these papers. The reasons for the high prevalence in Espírito Santo Bay are unknown, but may be due in part to the environmental degradation as confirmed by EEI (Herbst 1994, Herbst \& Klein 1995, Aguirre \& Lutz 2004). However, management of this disease will be difficult until we can determine the cause of FP. We do not suspect that turtles migrate between the control and FP-endemic area based on tagging data (TAMAR's database). We have no data on recruitment of sea turtles in Brazil. The CCL size of recruitment in green turtles is 30 to $40 \mathrm{~cm}$ (Musick \& Limpus 1997), and $48 \%$ of the individuals from FP site are between 30 and $40 \mathrm{~cm}$. The control area is an oceanic island and turtles smaller than $20 \mathrm{~cm}$ were captured there; based on this, we suspect that direct recruitment from the ocean occurs in both areas. 
The relation between size and prevalence of FP in this study agreed with findings of others for Brazil (Baptistotte 2007) and Florida (Foley et al. 2005, Hirama \& Ehrhart 2007) who found a similar relationship. There is an increase in prevalence up to the 80 to $85 \mathrm{~cm}$ size class in Indonesia (Adnyana et al. 1997), and in Hawaii the prevalence increases with the length of the carapace (Balazs 1991, Chaloupka \& Balazs 2005). Two potential explanations, already proposed by Herbst (1994), can be presented for the absence of FP in smaller size classes and the higher prevalence in larger size classes of turtles: (1) The exposure to one or more etiologic agents occurs in the pelagic zone, and the disease has a long latency period manifesting its first clinical signs only in the older juvenile phases; (2) the exposure to the etiologic agents occurs after juvenile recruitment to the neritic zone. It has clearly been shown in this and other studies (e.g. Herbst 1994, Hirama \& Ehrhart 2007) that FP has an environmental component. The absence of tumors in the smallest size class of neritic green turtles, concomitant with increasing prevalence of disease with age in turtles as found in Florida (Hirama \& Ehrhart 2007) and Hawaii (Balazs 1991), support the hypothesis that the agent responsible for FP is either acquired or triggered by some factor(s) in the neritic zone (Ehrhart 1991, Herbst \& Klein 1995, Foley et al. 2005). However, until we determine the actual cause of FP, sorting out these 2 hypotheses will be difficult. Lower prevalence of FP in larger size classes can be explained by mortality prior to reaching these size classes, or by the ability of these size classes to recover from the disease (Work et al. 2004, Foley et al. 2005). Determining the size classes of turtles that strand or die may help explain the relative importance of FP as a cause of stranding and mortality of sea turtles in Brazil.

We found no difference in body condition between FPS categories, thus the body condition index as applied in this study was not sensitive enough to detect differences. Other studies (Work \& Balazs 1999) have shown that FP definitely imposes negative costs on physiology of sea turtles, and FP is the most common cause of stranding in sea turtles in Hawaii (Chaloupka et al. 2008). Between 2000 and 2006, Torezani et al. (2009) conducted a study on the growth rate of green turtles in a region receiving effluent from a smelting company, and found lower growth rate for animals with FP. Chaloupka \& Balazs (2005) also found a lower growth rate in individuals with FPS-3 when compared to those that did not manifest the disease. Another possible related factor is the large availability of food in the area, which would allow severely affected animals to maintain a healthier body condition. Abundance of algae may be related to the discharge of organic matter from sewers in the area; indeed, local public ser- vants remove tons of seaweeds monthly from the beach in the area.

Most turtles in our study site fell under FPS-2 or FPS3 categories, indicating that FP is a severe problem in Espírito Santo Bay. This situation contrasts with the findings of Hirama \& Ehrhart (2007) in Florida, where, despite the higher prevalence of FP (61.6\%), individuals with FPS-1 represented $52.3 \%$ of individuals with FP, whereas those with FPS-3 only represented 15.2\%. In Florida, like Brazil, there are areas where FP prevalence is higher; however, unlike in this study, assessment of habitat quality has not been done in Florida. We also know that there are geographic variations in the way FP manifests in sea turtles (Ehrhart 1991, Herbst 1994, Hirama \& Ehrhart, 2007). Perhaps the high prevalence in our study site is because the disease has only appeared recently in sea turtles there, whereas in Florida the disease has been present since 1928 , thereby allowing animals to develop immunity to the etiologic agent.

In our study, FP affects mainly the anterior and posterior portions of soft skin; carapace/plastron was affected only in turtles with the highest proliferation of tumors. This contrasts to turtles in Indonesia (Adnyana et al. 1997), where the disease affects mainly the posterior of the animals. In a separate study, where FP was investigated in a region receiving effluent from a smelting company in Brazil, the anterior portion of turtles was most often affected (Baptistotte 2007). In Hawaii (Work et al. 2004), FP affects mainly the anterior portion and the eyes. In contrast to Florida (Herbst 1994) and Hawaii (Work et al. 2004), internal tumors were not found in our study area, and this may in part explain why we saw no difference in body condition of turtles with varying severity of FP. Given our sample size (11 necropsied turtles with tumor score 2 or 3), the upper $95 \%$ confidence limit for the maximum likely prevalence of internal tumors would have been $23 \%$ at our study site (Post \& Millest 1991). In studies done between 2000 and 2005 in Espírito Santo, Baptistotte (2007) found internal tumors in $13 \%$ of the 39 green turtles with FP and suggested that this topic merits further investigation in Brazil. Internal tumors can lead to cardiac dysfunction, buoyancy problems, respiratory compromise and gastrointestinal obstruction (Herbst 1994), all of which could negatively affect body condition.

Oral tumors are a serious threat to Hawaiian green turtle populations (Aguirre et al. 2002), though they were not seen in the current study and are rare in the Atlantic, where they were documented only twice in Florida (Hirama \& Ehrhart 2007) and once in Brazil (Baptistotte 2007). Eye tumors are also considered a serious threat because they directly affect the feeding and mobility of the animals (Balazs 1991, Jacobson et 
al. 1991). We saw no differences in the body condition of animals with and without ocular tumors. The fact that no relation was found between animal health and eye tumors agrees with what was found in Florida (Hirama \& Ehrhart 2007), although it does differ from the situation in the Pacific where these tumors appear to have a more clear effect on the health and survival of animals (Adnyana et al. 1997, Aguirre et al. 2002). The differences observed in manifestation of the disease between the Atlantic and the Pacific regions might be related to genomic variation in the suspected causative agent, cheloniid fibropapilloma-associated herpesvirus (CFPHV). Greenblatt et al. (2005) reports the existence of 4 varieties of the herpesvirus associated with FP: Atlantic group (Florida and Barbados), mid-Pacific group (Hawaii), west Pacific group (Australia) and east Pacific group (Costa Rica and California). Greenblatt et al. (2005) also showed that the Atlantic group displays a $0.98 \%$ genetic divergence from the west Pacific group and mid-Pacific group, which may help to explain the difference in the manifestation of the disease between the Atlantic and the 2 other Pacific regions.

Two strands of evidence suggest that FP in Espírito Santo Bay is severe compared to other areas like Hawaii, where the disease is on the decline (Chaloupka et al. 2009). First, the incidence of the disease $(41 \%)$ is high relative to prevalence (58\%). Second, the severity of disease either remained the same or increased in the majority of turtles that were recaptured. Although we had 3 turtles go from FPS-3 to FPS-2, this classification is debatable; when tumor size regressed, the numbers of tumors on these particular animals increased. This highlights the fact that the tumor score still has a degree of subjectivity that renders it a less than perfect tool. Nevertheless, this system has proved useful in measuring the severity and impact of disease on sea turtles in Brazil and other regions. The situation here contrasts with Florida (where fewer severely affected animals are present, and where cases of regression have been documented: Hirama \& Ehrhart 2007) and Hawaii (where the disease is actually decreasing: Chaloupka et al. 2009). That said, FP has only been studied in this region for $2 \mathrm{yr}$, and additional monitoring will be necessary to evaluate whether these trends are secular. Nevertheless, the high prevalence at our study site lends urgency to the need for further studies to document the demographic impacts, causes and pathogenesis of FP in Brazil.

Acknowledgements. We thank the FAPES, CAPES, TAMAR/ ICMBio and CNPq (ASM grant 308867/2006-8) for the financial support, the TAMAR team for helping with the field work, Acqua Sub and its team for lending SCUBA equipment and helping in the collecting of macroalgae.

\section{LITERATURE CITED}

Adnyana W, Ladds PW, Blair D (1997) Observations of fibropapillomatosis in green turtles (Chelonia mydas) in Indonesia. Aust Vet J 75:737-742

Aguirre AA, Balazs GH (2000) Blood biochemistry values of green turtles, Chelonia mydas, with and without fibropapillomatosis. Comp Haematol Int 10:132-137

Aguirre AA, Lutz PL (2004) Marine turtles as sentinels of ecosystem health: Is fibropapillomatosis an indicator? EcoHealth 1:275-283

Aguirre AA, Spraker TR, Balazs GH, Zimmerman B (1998) Spirorchidiasis and fibropapillomatosis in green turtles of the Hawaiian Islands. J Wildl Dis 34:91-98

Aguirre AA, Spraker TR, Murakawa S, Zimmerman B (2002) Pathology of oropharyngeal fibropapillomatosis in green turtles Chelonia mydas. J Aquat Anim Health 14:298-304

Balazs GH (1991) Current status of fibropapillomas in the Hawaiian green turtle, Chelonia mydas. In: Balazs GH, Pooley SG (eds) Research plan for marine turtle fibropapilloma, U.S. Dep. Commer. NOAA Tech Memo NMFSSWFSC-156, p 47-57

> Ballesteros E, Torras X, Pinedo S, García M, Mangialajo L, Torres M (2007) A new methodology based on littoral community cartography dominated by macroalgae for the implementation of the European Water Framework Directive. Mar Pollut Bull 55:172-180

Baptistotte C (2007) Caracterização espacial e temporal da fibropapilomatose em tartarugas marinhas da costa brasileira. PhD dissertation, Universidade de São Paulo Escola Superior de Agricultura 'Luiz de Queiroz', Piracicaba

Baptistotte C, Scalfoni JT, Gallo BMG, Santos AS and others (2001) Prevalence of sea turtle fibropapilomatosis in Brazil. In: Coyne MS, Clark RD (eds) Proceedings of the twentyfirst annual symposium on sea turtle biology and conservation. NOAA Tech Memo NMFS-SEFSC-528, p 111-113

Bellini C (1996) Reproduction and feeding of marine turtles in the Fernando de Noronha archipelago, Brazil. Mar Turtle Newsl 74:12-13

Bjorndal KA (1997) Foraging ecology and nutrition of sea turtles. In: Lutz P, Musick J (eds.) The biology of sea turtles. CRC Press, Boca Raton, FL, p 199-232

Bjorndal KA, Bolten AB (1989) Comparison of straight-line and over-the-curve measurements for growth rates of green turtles, Chelonia mydas. Bull Mar Sci 45:189-192

Bjorndal KA, Bolten AB, Chaloupka MY (2000) Green turtle somatic growth model: evidence for density dependence. Ecol Appl 10:269-282

Chaloupka M, Balazs GH (2005) Modelling the effect of fibropapilloma disease on somatic growth dynamics of Hawaiian green sea turtles. Mar Biol 147:1251-1260

Chaloupka M, Work T, Balazs G, Murakawa SKK, Morris R (2008) Cause-specific temporal and spatial trends in green sea turtle strandings in the Hawaiian Archipelago (1982-2003). Mar Biol 154:887-898

Chaloupka M, Balazs GH, Work TM (2009) Rise and fall over 26 years of a marine epizootic in Hawaiian green sea turtles. J Wildl Dis 45:1138-1142

Clarke KR (1993) Non-parametric multivariate analyses of changes in community structure. Aust J Ecol 18:117-143

> Daszak P, Cunningham AA, Hyatt AD (2000) Emerging infectious diseases of wildlife: threats to biodiversity and human health. Science 287:443-449

> Deem SL, Karesh WB, Weisman W (2001) Putting theory into practice: wildlife health in conservation. Conserv Biol 15:1224-1233 
Ehrhart LM (1991) Fibropapillomas in green turtles of the Indian River Lagoon, Florida: distribution over time and area. In: Balazs GH, Pooley SG (eds) Research plan for marine turtle fibropapilloma. US Dept Commer, NOAA Tech Memo NMFS-SFSC-156, p 59-61

Foley AM, Schroeder BA, Redlow AE, Fick-Child KJ, Teas WG (2005) Fibropapillomatosis in stranded green turtles (Chelonia mydas) from the eastern United States (1980-1998): trends and associations with environmental actors. J Wildl Dis 41:29-41

George R (1997) Health problems and diseases of sea turtles. In: Lutz P, Musick J (eds) The biology of sea turtles, CRC Press, Cleveland, OH, p 363-385

> Godley BJ, Lima EHSM, Akesson S, Broderick AC and others (2003) Movement patterns of green turtles in Brazilian coastal waters described by satellite tracking and flipper tagging. Mar Ecol Prog Ser 253:279-288

Gorostiaga JM, Díez I (1996) Changes in the sublittoral benthic marine macroalgae in the polluted area of Abra de Bilbao and proximal coast (northern Spain). Mar Ecol Prog Ser 130:157-167

Greenblatt RJ, Quackenbush SL, Casey RN, Rovnak J and others (2005) Genomic variation of the fibropapillomaassociated marine turtle herpesvirus across seven geographic areas and three host species. J Virol 79:1125-1132

Herbst LH (1994) Fibropapillomatosis of marine turtles. Annu Rev Fish Dis 4:389-425

Herbst LH, Klein PA (1995) Green turtle fibropapillomatosis: challenges to assessing the role of environmental cofactors. Environ Health Perspect 103:27-30

Hirama S, Ehrhart LM (2007) Description, prevalence and severity of green turtle fibropapillomatosis in three developmental habitats on the east coast of Florida. Fla Sci 70 : 435-448

Horta PA, Amâncio E, Coimbra CS, Oliveira EC (2001) Considerações sobre a distribuição e origem da flora de macroalgas brasileiras. Hoehnea 28:243-265

Jacobson ER, Buergelt C, Williams B, Harris RK (1991) Herpesvirus in cutaneous fibropapillomas of the green turtle Chelonia mydas. Dis Aquat Org 12:1-6

Kruskal JB, Wish M (1978) Multidimensional scaling. Sage Publications, Beverley Hills, CA

Magurran AE (1991) Ecological diversity and its measurement. Chapman \& Hall, London

Moreira L, Baptistotte C, Scalfone J, Thomé CJ, de Almeida APLS (1995) Occurrence of Chelonia mydas on the Island of Trindade, Brazil. Mar Turtle Newsl 70:2

> Murray SN, Litter MM (1978) Patterns of algal succession in a perturbated marine intertidal community. J Phycol 14: 506-512

Editorial responsibility: Julie Bebak, Auburn, Alabama, USA
Murray SN, Ambrose RF, Dethier MN (2002) Methods for performing monitoring, impact, and ecological studies on rocky shores. US Dept Interior, Minerals Management Service, Pacific OCS Region, Camarillo, CA

Musick JA, Limpus CJ (1997) Habitat utilization and migration in juvenile sea turtles. In: Lutz P, Musick J (eds) The biology of sea turtles. CRC Press, Cleveland, $\mathrm{OH}$, p 137-163

Orfanidis S, Panayotidis P, Stamatis N (2001) Ecological evaluation of transitional and coastal waters: a marine benthic macrophytes-based model. Medit Mar Sci 2:45-65

Orfanidis S, Panayotidis P, Stamatis N (2003) An insight to ecological evaluation index (EEI). Ecol Indic 3:27-33

Panayotidis P, Montesanto B, Orfanidis S (2004) Use of lowbudget monitoring of macroalgae to implement the European Water Framework Directive. J Appl Phycol 16:49-59

Post RJ, Millest AL (1991) Sample size in parasitological vector surveys. Parasitol Today 7:141

Quackenbush SL, Work TM, Balazs GH, Casey RN and others (1998) Three closely related herpesviruses are associated with fibropapillomatosis in marine turtles. Virology 246: 392-399

Seminoff JA (2004) Chelonia mydas. In: IUCN 2008. 2008 IUCN Red List of Threatened Species. www.iucnredlist. org (Downloaded on 24 December 2008)

Torezani E, Baptistotte C, Mendes SR, Barata PCR (2009) Juvenile green turtles (Chelonia mydas) in the effluent discharge channel of a steel plant, Espírito Santo, Brazil, 2000-2006. J Mar Biol Assoc UK, doi:10.1017/S0025315409990579

- Work TM, Balazs GH (1999) Relating tumor score to hematology in green turtles with fibropapillomatosis in Hawaii. J Wildl Dis 35:804-807

Work TM, Rameyer RA, Balazs GH, Cray C, Chang SP (2001) Immune status of free-ranging green turtles with fibropapillomatosis from Hawaii. J Wildl Dis 37:574-581

Work TM, Balazs GH, Wolcott M, Morris RA (2003) Bacteraemia in free-ranging Hawaiian green turtles Chelonia mydas with fibropapillomatosis. Dis Aquat Org 53:41-46

Work TM, Balazs GH, Rameyer RA, Morris RA (2004) Retrospective pathology survey of green turtles Chelonia mydas with fibropapillomatosis in the Hawaiian Islands, 1993-2003. Dis Aquat Org 62:163-176

> Work TM, Balazs GH, Schumacher J, Marie A (2005) Epizootiology of spirorchid infection in green turtles (Chelonia mydas) in Hawaii. J Parasitol 91:871-876

Worm B, Barbier EB, Beaumont N, Duffy JE and others (2006) Impacts of biodiversity loss on ocean ecosystem services. Science 314:787-790

Submitted: March 27, 2009; Accepted: November 10, 2009 Proofs received from author(s): February 12, 2010 